Review Article

\title{
An Update on the Safety and Efficacy of Corneal Collagen Cross-Linking in Pediatric Keratoconus
}

\author{
Hala El Rami, ${ }^{1}$ Elias Chelala, ${ }^{1}$ Ali Dirani, ${ }^{1,2}$ Ali Fadlallah,, ${ }^{1,2}$ Henry Fakhoury, \\ Carole Cherfan, ${ }^{2}$ George Cherfan, ${ }^{2}$ and Elias Jarade ${ }^{2,3}$ \\ ${ }^{1}$ Faculty of Medicine, Saint-Joseph University, P.O. Box 11-5076, Riad El Solh, Beirut 1107 2180, Lebanon \\ ${ }^{2}$ Beirut Eye Specialist Hospital, P.O. Box 116-5311, Beirut, Lebanon \\ ${ }^{3}$ Mediclinic, Dubai Mall, Dubai, UAE \\ Correspondence should be addressed to Elias Jarade; ejarade@yahoo.com
}

Received 28 February 2015; Accepted 6 September 2015

Academic Editor: Jose Manuel González-Méijome

Copyright (C) 2015 Hala El Rami et al. This is an open access article distributed under the Creative Commons Attribution License, which permits unrestricted use, distribution, and reproduction in any medium, provided the original work is properly cited.

\begin{abstract}
Keratoconus is a degenerative disease that affects adolescents and young adults and presents with variable thinning and conical deformation of the corneal apex. The resultant irregular astigmatism can progress to levels that can significantly affect everyday activities and overall quality of life. Therefore, stopping the progression of the disease is an essential part in managing patients with keratoconus. Corneal collagen cross-linking is a minimally invasive procedure that stiffens the anterior corneal stroma by creating strong covalent bonds between collagen fibrils. Over the past decade, many studies have proved its safety and efficacy in halting keratoconus progression in adults. This review of the literature highlights the growing trend towards using this treatment in pediatric keratoconic patients. In children, keratoconus tends to be more severe and fast progression is often encountered requiring closer follow-up intervals. Standard cross-linking shows comparable results in children with a good safety-efficacy profile during follow-up periods of up to three years. Further research is needed to standardize and evaluate transepithelial and accelerated crosslinking protocols as these could be of tremendous help in a population where cooperation and compliance are major issues.
\end{abstract}

\section{Introduction}

Keratoconus is a noninflammatory progressive degeneration of the cornea. It is characterized by bilateral often asymmetric thinning and conical protrusion of the corneal apex which account for irregular astigmatism and poor visual acuity [1, 2]. Its onset is classically around puberty, and progression is maximal during adolescence and early adulthood. When left untreated, spontaneous stabilization may occur during the third to fourth decade due to natural history of the disease, and stiffening of the corneal stroma by an increase in the number of cross-links between collagen fibrils may occur $[3,4]$. Unfortunately, the progression of keratoconus for years before final stabilization may result in severe corneal scarring, and keratoplasty is the only treatment option left in up to $20 \%$ of patients $[5,6]$.

In an attempt to mimic the natural biomechanical stiffening that occurs with ageing, corneal collagen cross-linking with irradiated riboflavin was first introduced in the late $90 \mathrm{~s}$ by Spörl et al. [7]. It induced the formation of strong covalent bonds between stromal collagen fibrils leading to a longlasting increase in the biomechanical rigidity of the cornea $[8$, 9]. Nowadays, collagen cross-linking is an important asset in the management of keratoconus as a series of peer-reviewed studies have demonstrated its safety and efficacy in halting the progression of the disease and avoiding the need for corneal transplantation [10-15]. Some improvement in visual acuity, flattening of keratometric readings, and reduction in comatic aberrations have also been reported following cross-linking [12-15].

The encouraging safety-efficacy profile with follow-up ranging between 5 and 10 years in some series [13-15] has led many authors to consider cross-linking in pediatric patients and a rising number of reports on such attempts are being published. This review is intended to summarize 
the application and current status of corneal collagen crosslinking in pediatric keratoconus.

\section{Epidemiology and Clinical Presentation of Keratoconus}

The prevalence of keratoconus varies among different populations with an estimate of approximately 1/2000 individuals $[1,2]$.

It is often an isolated disease that is diagnosed in otherwise healthy subjects. However, systemic and/or ocular associations such as atopy, vernal keratoconjunctivitis, Down syndrome, retinitis pigmentosa, Leber congenital amaurosis, mitral valve prolapse, and noninflammatory connective tissue disorders such as Marfan and Ehlers-Danlos syndromes have been reported $[1,2,16]$.

A genetic basis for keratoconus has been suspected and several candidate genes, including those coding for different types of collagen and proteinase inhibitors as well as antioxidant genes, have been investigated. Family history is classically found in up to $10 \%$ of patients [16-18]. This probably underestimates the true familial incidence of keratoconus as it does not take into account the subclinical disease known as "forme fruste" which corresponds to asymptomatic early stage keratoconus detected solely by means of modern corneal topography analysis and without evidence of progression over time [19]. When taking subclinical forms into account, first degree relatives have an estimated 15 to 67 times higher prevalence of keratoconus than that in the general population [20].

The disease usually starts at puberty. However, according to the CLEK study, the mean age at diagnosis is $27.3 \pm 9.5$ years and $90 \%$ of patients are diagnosed as early as 10 years of age or as late as 39 years of age [21]. This is due to the previously outlined highly variable expressivity of keratoconus with a small percent of patients (1\%) having a "forme fruste" for a lifetime with good visual acuity and other patients progressing to stage 4 disease while still in their early twenties [22].

Clinical findings suggestive of keratoconus are as follows: progressive myopia and/or astigmatism with frequent change of glasses, suboptimal refraction suggesting the irregular nature of cylinder, scissoring of the red reflex, slit lamp examination showing thinning, apical protrusion, prominent corneal nerves, Vogt striae, Fleischer rings, and/or anterior stromal opacifications. Diagnosis is confirmed with corneal topography which typically shows the following: inferior to superior power asymmetry of more than $1.5 \mathrm{D}$, skewing of more than 20 degrees of the steepest radial axis above and below the horizontal meridian, and thin corneas with an inferotemporal displacement of "remarkable points," such as the thinnest pachymetry, the steepest anterior, and the steepest posterior points. The definitive diagnosis will be based on a combination of clinical findings and topographic findings.

\section{Main Characteristics of Keratoconus in the Pediatric Population}

At presentation, the amount of visual impairment is variable and usually asymmetric in children with keratoconus.
However, it rarely results in amblyopia because the development of visual function is completed at approximately 10 years of age. Many children have a history of eye rubbing and vernal keratoconjunctivitis.

At the time of diagnosis, the disease stage seems to be more advanced in younger patients. In a study of 476 eyes of 248 consecutive patients diagnosed with keratoconus, $17.2 \%$ were less than 20 years old and in this subgroup of patients, clinical findings were more severe [23]. In the study by LéoniMesplié et al., $27.8 \%$ of patients $\leq 15$ years old had an AmslerKrumeich stage 4 disease compared to $7.8 \%$ of patients $\geq 27$ years old [24]. Deterioration in pediatric keratoconus occurs more frequently compared to adults with keratoconus. In a population of 1032 patients followed by the CLEK study group, progression occurred in $24 \%$ of cases and was maximal in patients less than 20 years old and minimal after 30 years of age [25]. Furthermore, recent studies have demonstrated more debilitating progression patterns with an increased likelihood of corneal opacities [26, 27] and keratoplasty [28, 29] in younger age patients.

\section{Indications and Inclusion Criteria for Corneal Cross-Linking in Pediatric Keratoconus}

In all published studies, emphasis was made about the documented progression of keratoconus prior to cross-linking. No clear definition for progression was found and each study defined its own progression criteria, summarized in Table 1. Progressive steepening, worsening asymmetry of keratometric readings, and decrease in central and/or thinnest pachymetry on consecutive measurements seem to be the most significant to consider when looking for deterioration as ametropia may change independently of keratoconus in children.

Keratoconus in patients less than 18 years old tends to be more aggressive and as previously outlined, severe deterioration is not exceptional. Therefore, rapid decision making is mandatory. Soeters et al. [38] diagnose progression in children within a 1 to 3 months' follow-up period versus 6 to 12 months' follow-up period in adolescents and adults while Chatzis and Hafezi [34] advise not to wait for progression to cross-link young corneas when the individual benefits outweigh the risks (i.e., severe disease in fellow eye, family history of progression to stage III-IV, family history of keratoplasty, etc.).

The major reported inclusion criteria for cross-linking in children with keratoconus were basically the same criteria reported for adults and included the following: thinnest pachymetry of more than $400 \mu \mathrm{m}$ [32-41], absence of corneal opacities [30, 32, 33, 35-43], no history of herpetic keratitis $[32,33,36,37,39-41]$, absence of concurrent corneal infections $[32,33,36,37,41]$, absence of severe dry eyes [32, 33, $36,40,41$ ], absence of severe vernal keratoconjunctivitis [40], absence of concomitant autoimmune disease [32, 33, 36, 40], no history of previous ocular surgery [32, 33, 36, 38-41], and endothelial cell count of more than 1000 cells $/ \mathrm{mm}^{2}$ [33]. 
TABLE 1: Variability of the criteria used to define keratoconus progression in different studies.

\begin{tabular}{|c|c|c|c|c|c|c|}
\hline Study & Visual acuity & Refraction & Keratometry & Pachymetry & Topography & Considerations \\
\hline $\begin{array}{l}\text { Caporossi et } \\
\text { al. [30] }\end{array}$ & $\begin{array}{c}\text { UCVA/BSCVA } \\
\text { decrease } \geq 1 \\
\text { Snellen line }\end{array}$ & $\begin{array}{c}\Delta \text { Sph or } \Delta \mathrm{Cyl} \\
>0.5 \mathrm{D}\end{array}$ & $\Delta K_{\text {mean }}>0.5 \mathrm{D}$ & $\begin{array}{c}\text { Decrease in } \\
\text { thinnest } \\
\text { pachymetry } \geq \\
10 \mu \mathrm{m} \\
\end{array}$ & $\begin{array}{c}\Delta \mathrm{SAI} / \mathrm{SI}> \\
0.5 \mathrm{D}\end{array}$ & $\begin{array}{l}\text { At least } 2 \text { parameters } \\
\text { in } 3 \text { months }\end{array}$ \\
\hline $\begin{array}{l}\text { Caporossi et } \\
\text { al. [31] }\end{array}$ & $\begin{array}{l}\text { UCVA/BSCVA } \\
\text { decrease } \geq 1 \\
\text { Snellen line }\end{array}$ & $\begin{array}{c}\Delta \text { Sph or } \Delta \mathrm{Cyl} \\
>0.5 \mathrm{D}\end{array}$ & $\Delta K_{\max }>1 \mathrm{D}$ & $\begin{array}{c}\text { Decrease in } \\
\text { thinnest } \\
\text { pachymetry } \geq \\
10 \mu \mathrm{m}\end{array}$ & $\begin{array}{c}\Delta \mathrm{SAI} / \mathrm{SI}> \\
0.5 \mathrm{D}\end{array}$ & $\begin{array}{c}\text { At least } 3 \text { parameters } \\
\text { (1 clinical and } 2 \\
\text { instrumental) in } 3 \\
\text { months }\end{array}$ \\
\hline $\begin{array}{l}\text { Vinciguerra } \\
\text { et al. [32] }\end{array}$ & & $\begin{array}{c}\text { Change in } \\
\text { Sph or Cyl } \geq \\
\text { 3D }\end{array}$ & $\begin{array}{c}\Delta K_{\text {mean }} \geq 1.5 \mathrm{D} \\
\text { on } 2 \text { consecutive } \\
\text { topographies }\end{array}$ & $\begin{array}{c}\text { Decrease in CCT } \\
\geq 5 \% \text { on } 3 \\
\text { consecutive } \\
\text { tomographies }\end{array}$ & & $\begin{array}{c}\text { Any parameter in } 3 \\
\text { months }\end{array}$ \\
\hline $\begin{array}{l}\text { Zotta et al. } \\
{[33]}\end{array}$ & & $\Delta \mathrm{SE}>0.75 \mathrm{D}$ & $\begin{array}{l}\Delta K_{\max } \text { of cone } \\
\text { apex }>0.75 \mathrm{D}\end{array}$ & & & $\begin{array}{c}\text { Any parameter in } 6 \\
\text { months }\end{array}$ \\
\hline $\begin{array}{l}\text { Chatzis and } \\
\text { Hafezi [34] }\end{array}$ & & & $\Delta K_{\max }>1 \mathrm{D}$ & & & $\begin{array}{l}\text { Follow-up period of } \\
\text { maximum } 12 \text { months }\end{array}$ \\
\hline $\begin{array}{l}\text { Bakshi et al. } \\
\text { [35] }\end{array}$ & & $\Delta \mathrm{Cyl} \geq 1.5 \mathrm{D}$ & $\Delta K_{\max } \geq 1.5 \mathrm{D}$ & & & $\begin{array}{c}\text { Any parameter at } 3 \\
\text { time points in } 12 \\
\text { months }\end{array}$ \\
\hline $\begin{array}{l}\text { Magli et al. } \\
{[36]}\end{array}$ & & $\Delta \mathrm{Cyl}>1 \mathrm{D}$ & $\begin{array}{c}\Delta K_{\max } \text { of cone } \\
\text { apex }>1 \mathrm{D}\end{array}$ & & & $\begin{array}{c}\text { Any parameter in } 6 \\
\text { months }\end{array}$ \\
\hline $\begin{array}{l}\text { Shetty et al. } \\
{[32,37]}\end{array}$ & & & $\begin{array}{c}\Delta K_{\max }>1-1.5 \mathrm{D} \\
\text { with } \\
\text { corresponding } \\
\text { change in } \\
\text { refraction } \\
\end{array}$ & $\begin{array}{c}\text { Decrease in } \\
\text { thinnest } \\
\text { pachymetry } \geq 5 \%\end{array}$ & & $\begin{array}{c}\text { Any parameter in } 6 \\
\text { months }\end{array}$ \\
\hline $\begin{array}{l}\text { Zotta et al. } \\
\text { [33] }\end{array}$ & & $\begin{array}{c}\Delta \mathrm{Cyl} \geq 1 \mathrm{D} \\
\text { and } \Delta \mathrm{SE} \geq \\
0.5 \mathrm{D}\end{array}$ & $\Delta K_{\max } \geq 1 \mathrm{D}$ & & & $\begin{array}{c}\text { All } 3 \text { parameters on } \\
\text { consecutive } \\
\text { examinations }\end{array}$ \\
\hline
\end{tabular}

UCVA: uncorrected visual acuity, BSCVA: best spectacle corrected visual acuity, Sph: sphere, Cyl: cylinder, SAI: surface asymmetry index, SI: symmetry index, CCT: central corneal thickness, SE: spherical equivalent, and $\Delta$ : increase in.

\section{Corneal Cross-Linking Techniques in Children}

In the reported studies, all procedures were performed under topical anesthesia except in the study by Arora et al. [40] where general anesthesia was necessary in 8 out of 15 patients due to lack of cooperation. Premedication with 1 to $2 \%$ topical pilocarpine in the eye to be treated was often performed to induce a myotic pupil and protect the crystalline lens and posterior pole from light exposure.

The standard Dresden cross-linking protocol was carried out in most studies [31-36, 38, 40,43] and consisted of the following:

(1) Eight to $9 \mathrm{~mm}$ central epithelial debridement (Epi-Off technique) with a blunt metal spatula or a soft brush.

(2) Photosensitization with an isotonic $0.1 \%$ Riboflavin mixed with $20 \%$ dextran solution, usually for 30 minutes before irradiation and then every 2 to 5 minutes during irradiation to maintain saturation of the cornea. In the study by Kodavoor et al. [43], hypotonic riboflavin was used in patients with thinnest pachymetry below $400 \mu \mathrm{m}$, with the cutoff level being $350 \mu \mathrm{m}$. In the study by Arora et al. [40], ultrasound pachymetry was repeatedly performed during the procedure, and hypotonic riboflavin was administered every 10 seconds during two minutes whenever pachymetry dropped below $400 \mu \mathrm{m}$. This minimal corneal thickness has to be maintained throughout the procedure to avoid harmful endothelial side effects that would occur if oxygen radicals were created too deep (as in shallow corneas).

(3) Uniform ultraviolet A irradiation at $3 \mathrm{~mW} / \mathrm{cm}^{2}$ for 30 minutes, accounting for a surface dose of $5.4 \mathrm{~J} / \mathrm{cm}^{2}$. The masking of the limbus and/or the treatment zone diameter were carefully selected to protect the limbal stem cells from the toxic effects of oxygen radicals generated by the procedure.

Other nonstandard techniques were also performed in children:

(1) Transepithelial crosslinking (Epi-ON technique) [31, $36,41,42]$ : the epithelium was not removed and the riboflavin solution was supplemented with the epithelial penetration enhancers trishydroxymethyl aminomethane and sodium EDTA. 
(2) Accelerated cross-linking [37, 39]: a higher irradiance was delivered to reduce exposure time (i.e., $9 \mathrm{~mW} / \mathrm{cm}^{2}$ for 10 minutes [37] or $30 \mathrm{~mW} / \mathrm{cm}^{2}$ for 4 minutes [39] instead of $3 \mathrm{~mW} / \mathrm{cm}^{2}$ for 30 minutes).

At the end of the cross-linking procedure, a bandage contact lens was applied and removed after complete epithelialization. A topical treatment with artificial tears, steroids, and antibiotics was prescribed.

\section{Published Results of Corneal Cross-Linking in Pediatric Keratoconus}

Studies' methodology, demographics, and overall safetyefficacy results are summarized in Table 2. Studies examining UVA cross-linking as a safe and effective modality in stabilizing keratoconus have been conducted in adults in the late nineties with preliminary results first published around 2003 [44]. Since then, numerous prospective trials have proved its long-term safety and efficacy in adults [10-15]. Data on cross-linking in children and young adolescents are scarce with only fourteen peer-reviewed studies reported so far [30-43]. This is explained by the fact that the studying of interventional procedures is more appropriate in a group of patients who are old enough to understand the nature of treatment and to get an informed consent.

6.1. Safety of Corneal Collagen Cross-Linking. Cross-linking showed a good safety profile in children, and no major complications have been reported with both standard and nonstandard techniques. Postoperative haze was often transient and resolved with no sequelae on topical steroids $[32,37$, 40] except in the studies by Soeters et al. [38] and Kodavoor et al. [43] where significant haze occurred in $3.57 \%$ ( 2 out of 56 eyes) and $14.28 \%$ (5 out of 35 eyes) of patients, respectively. Delayed epithelialization of up to 10 days $[34,40]$ and transient glare and corneal edema [36] were also reported. There was no statistically significant loss in endothelial cell counts after cross-linking both in standard and accelerated techniques [32, 36, 37, 39, 41, 43]. However, longer follow-up periods are needed to make sure that the endothelial function does not suffer from any delayed side effects.

6.2. Efficacy of the Standard Cross-Linking Protocol. When performed with the standard protocol, cross-linking stabilized the disease process during the follow-up period which ranged between 12 and 36 months. When progression occurred despite cross-linking (one eye in the study by Chatzis and Hafezi [34] and 3 eyes in the study by Kodavoor et al. [43]), it was associated with persistent eye rubbing and/or vernal keratoconjunctivitis. Therefore, it is important to make sure that any underlying atopic disease that might contribute to later deterioration is well controlled at the time of cross-linking and the patient should be advised to stop rubbing his eyes. A redo cross-linking was performed by Chatzis and Hafezi [34] after 12 months of follow-up on the eye that showed progression. No significant complications occurred, the patient ceased eye rubbing, and he was stable at the 11 months' follow-up visit after redo cross-linking. Other reports have reported cases of adult patients who needed redo cross-linking [47, 48]. Risk factors associated with disease progression after cross-linking in these reports were the presence of neurodermatitis (associated with skin and eye rubbing) [47], female sex, and preoperative maximum $K$ readings superior to $58 \mathrm{D}$ [48].

Improvement in uncorrected visual acuity (UCVA), best spectacle corrected visual acuity (BSCVA), and a significant flattening in $K$-readings were reported. Pachymetry remained stable. Soeters et al. [38] reported more corneal flattening and more visual acuity improvement in children compared to adults while Vinciguerra et al. [32] found better functional and morphological results in the subgroup of patients between 18 and 39 years old. However, in the study by Chatzis and Hafezi [34], improvement in $K$-readings occurred until the 24 months' follow-up visit with a regression to preoperative values at the 36 months' follow-up visit suggesting a possible decrease in the efficacy of cross-linking over time. This was not observed by Caporossi et al. [30] or Zotta et al. [33] who also reported 36 months' follow-up results. In adult populations, studies reported a sustainable effect over follow-up periods of up to ten years [15]. Knowing that natural cross-linking may occur with ageing of the corneal tissues $[3,4]$ and the possibility of spontaneous stabilization of keratoconus with advanced age, it is difficult to attribute the long-lasting stability observed in adults to either the initial surgery or the natural history of the disease. Furthermore, in the pediatric age group, corneal collagen remodeling and lay down of new collagen fibers occur at a higher rate than in adult corneas; hence, lay down of weak ectatic lamellae may exceed the capacity of the cross-linking process. Therefore, studies with longer follow-up periods are mandatory when cross-linking is performed at a very young age as cross-linking is more likely to have an expiry date with subsequent relapse.

6.3. Efficacy of the Nonstandard Cross-Linking Protocols. It is interesting to consider the nonstandard cross-linking techniques as these might solve some major cooperation issues that clinicians face when treating children. A significant decrease in the length of the treatment with an accelerated procedure or a "no-touch" reassuring transepithelial protocol would certainly make cross-linking easier to perform under topical anesthesia in the pediatric population. The accelerated cross-linking procedure showed an overall improvement in visual acuity and flattening of $K$-readings both in pediatric and adult populations [37, 39, 49, 50]. Although positive results are reported, it seems that the depth of treatment reached in accelerated cross-linking is less than the one achieved with the conventional technique with a mean demarcation line found at an average depth between 100 and $240 \mu \mathrm{m}$ versus 300 and $350 \mu \mathrm{m}$ with standard crosslinking [51, 52]. This finding might be related to the fact that the optimal irradiance and fluence time have not been clearly defined yet, and treatment settings were different among studies. On the other hand, while postoperative pain seems less when an Epi-ON procedure is performed $[36,41]$, controversy remains over the efficacy of transepithelial crosslinking. Traditionally, the epithelium is debrided prior to 
TABLE 2: Cross-linking in pediatric keratoconus: summary of the studies' characteristics and overall results.

\begin{tabular}{|c|c|c|c|c|c|c|c|c|c|c|}
\hline Study & Type & $\begin{array}{c}N \\
\text { patients/eyes }\end{array}$ & $\begin{array}{l}\text { Age } \\
\text { (yrs.) }\end{array}$ & $\begin{array}{l}\mathrm{M} / \mathrm{F} \\
\text { ratio }\end{array}$ & $\begin{array}{c}\text { Amsler- } \\
\text { Krumeich } \\
\text { classification }\end{array}$ & $\begin{array}{l}\text { F-up before } \\
\text { CXL (mo.) }\end{array}$ & $\begin{array}{c}\text { CXL } \\
\text { Technique }\end{array}$ & $\begin{array}{l}\text { F-up after } \\
\text { CXL (mo.) }\end{array}$ & Safety & Efficacy \\
\hline $\begin{array}{l}\text { Caporossi et al. } \\
{[30]}\end{array}$ & $\mathrm{P}$ & $152 / 77$ & $10-18$ & $4 / 1$ & $\leq \mathrm{III}$ & $12-36$ & Standard & 36 & + & + \\
\hline $\begin{array}{l}\text { Caporossi et al. } \\
\text { [31] }\end{array}$ & $\mathrm{P}$ & $10 / 10$ & $11-18$ & & & & Transepithelial & 24 & + & - \\
\hline $\begin{array}{l}\text { Vinciguerra et } \\
\text { al. [32] }\end{array}$ & $\mathrm{P}$ & $40 / 40$ & $9-18$ & $31 / 9$ & II & 3 & Standard & 24 & + & + \\
\hline $\begin{array}{l}\text { Buzzonetti and } \\
\text { Petrocelli [42] }\end{array}$ & $\mathrm{P}$ & $13 / 13$ & $8-18$ & $12 / 1$ & $\leq \mathrm{III}$ & & Transepithelial & 18 & + & - \\
\hline Zotta et al. [33] & $\mathrm{R}$ & $4 / 8$ & $11-15$ & $1 / 3$ & & $6-9$ & Standard & 36 & + & + \\
\hline $\begin{array}{l}\text { Chatzis and } \\
\text { Hafezi [34] }\end{array}$ & $\mathrm{R}$ & $42 / 59$ & $9-19$ & $29 / 13$ & I-IV & & Standard & 36 & + & - \\
\hline Arora et al. [40] & $\mathrm{P}$ & $15 / 15$ & $10-15$ & & I-II & & Standard & 12 & + & + \\
\hline Bakshi et al. [35] & $\mathrm{R}$ & $9 / 9$ & $11-17$ & $1 / 0$ & & 12 & Standard & 24 & + & + \\
\hline Magli et al. [36] & $\mathrm{R}$ & $\begin{array}{l}19 / 23 \\
11 / 16 \\
\end{array}$ & $\begin{array}{l}12-17 \\
12-17 \\
\end{array}$ & $\begin{array}{c}14 / 5 \\
8 / 3 \\
\end{array}$ & & $\begin{array}{l}6 \\
6 \\
\end{array}$ & $\begin{array}{c}\text { Standard } \\
\text { Transepithelial }\end{array}$ & 12 & + & + \\
\hline Shetty et al. [37] & $\mathrm{P}$ & $18 / 30$ & $11-14$ & & & & $\begin{array}{c}\text { Accelerated } \\
9 \mathrm{~mW} / \mathrm{cm}^{2} \\
\text { for } 10 \text { minutes }\end{array}$ & 24 & + & + \\
\hline $\begin{array}{l}\text { Ozgurhan et al. } \\
\text { [39] }\end{array}$ & $\mathrm{R}$ & $38 / 44$ & $9-18$ & $14 / 5$ & & & $\begin{array}{c}\text { Accelerated } \\
30 \mathrm{~mW} / \mathrm{cm}^{2} \\
\text { for } 4 \text { minutes }\end{array}$ & 24 & + & + \\
\hline Salman [41] & $\mathrm{P}$ & $22 / 22$ & $13-18$ & $9 / 2$ & & 12 & Transepithelial & 12 & + & + \\
\hline $\begin{array}{l}\text { Soeters et al. } \\
{[38]}\end{array}$ & $\mathrm{P}$ & $-/ 31$ & $12-17$ & & & & Standard & 12 & + & + \\
\hline $\begin{array}{l}\text { Kodavoor et al. } \\
{[43]}\end{array}$ & $\mathrm{R}$ & $24 / 35$ & $9-16$ & & & & Standard & 12 & + & + \\
\hline $\begin{array}{l}\text { Viswanathan et } \\
\text { al. [45] }\end{array}$ & $\mathrm{P}$ & $18 / 25$ & $8-17$ & $13 / 5$ & I-III & & Standard & $6-48$ & + & + \\
\hline Sabti et al. [46] & $\mathrm{C}$ & $1 / 2$ & 4 & $1 / 0$ & & 3 & Standard & 36 & + & + \\
\hline
\end{tabular}

F-up: follow-up, CXL: cross-linking, P: prospective, R: retrospective, C: case report, (+): favorable outcome, and (-): unfavorable outcome.

cross-linking because of the small and uneven penetration of riboflavin through the tight epithelial junctions resulting in insufficient stromal concentration. In transepithelial crosslinking, epithelial penetration enhancers such as benzalkonium chloride, tetracaine, surfactants, trishydroxymethyl aminomethane, and/or sodium EDTA were added to the riboflavin-dextran solution. The primary objectives behind keeping the corneal epithelium in the transepithelial protocol were the reduction of postoperative pain and infectious risk and the added corneal thickness of about $50 \mu \mathrm{m}$, with possible reduction of phototoxicity and feasibility of crosslinking in thinner corneas. In the study by Magli et al. [36], transepithelial cross-linking was effective as no statistically significant difference was observed between standard and transepithelial techniques in terms of disease stabilization and improvement in children. The transepithelial procedure had fewer complications with less pain and no postoperative corneal edema. However, sample size was small (23 eyes in the transepithelial cross-linking group versus 16 eyes in the standard cross-linking group) and follow-up period was limited to only one year. Salman [41] found similar results in his small series of 22 eyes treated with transepithelial cross-linking and followed for a period of one year. Most authors reported progression of keratoconus in children and adults treated with the Epi-ON technique although transient improvement in keratoconus indices might occur [31, 42, 53]. Confocal microscopy performed on Epi-ON cross-linked corneas showed no significant modifications when compared to cross-linked corneas with standard or accelerated Epi-OFF protocols [51]. Some corneal stiffening was demonstrated in the study by Scarcelli et al. [54] on porcine corneas but it was $70 \%$ less pronounced than in Epi-OFF standard technique. In his study, corneal stiffening was strongly related to irradiance time suggesting that optimizing the light dose might increase the efficacy of the transepithelial protocol in future studies.

\section{Conclusion}

Keratoconus in children tends to be more severe than in adults and rapid deterioration can occur requiring more frequent follow-up intervals. Moreover, the decision to cross-link pediatric corneas should be prompt as studies 
have proved the safety and efficacy of the standard crosslinking protocol in halting disease progression. However, studies with larger samples and longer follow-up need to be performed to determine if stabilization is long-lasting in children. When dealing with patients younger than 14 years of age, compliance is a major issue making nonstandard accelerated or transepithelial protocols appeal to clinicians. More research is needed to determine and standardize the most effective treatment parameters for these protocols and randomized controlled trials would prove essential in comparing these techniques to the standard cross-linking protocol in terms of long-lasting efficacy.

\section{Conflict of Interests}

None of the authors has any proprietary, commercial, or financial interest in any of the products mentioned.

\section{Authors' Contribution}

Hala El Rami and Elias Chelala had similar contributions to this paper.

\section{References}

[1] Y. S. Rabinowitz, "Keratoconus," Survey of Ophthalmology, vol. 42, no. 4, pp. 297-319, 1998.

[2] A. E. Davidson, S. Hayes, A. J. Hardcastle, and S. J. Tuft, "The pathogenesis of keratoconus," Eye, vol. 28, no. 2, pp. 189-195, 2014.

[3] N. S. Malik, S. J. Moss, N. Ahmed, A. J. Furth, R. S. Wall, and K. M. Meek, "Ageing of the human corneal stroma: structural and biochemical changes," Biochimica et Biophysica Acta, vol. 1138, no. 3, pp. 222-228, 1992.

[4] A. Daxer, K. Misof, B. Grabner, A. Ettl, and P. Fratzl, "Collagen fibrils in the human corneal stroma: structure and aging," Investigative Ophthalmology and Visual Science, vol. 39, no. 3, pp. 644-648, 1998.

[5] W. E. Smiddy, T. R. Hamburg, G. P. Kracher, and W. J. Stark, "Keratoconus. Contact lens or keratoplasty?" Ophthalmology, vol. 95, no. 4, pp. 487-492, 1988.

[6] S. J. Tuft, L. C. Moodaley, W. M. Gregory, C. R. Davison, and R. J. Buckley, "Prognostic factors for the progression of keratoconus," Ophthalmology, vol. 101, no. 3, pp. 439-447, 1994.

[7] E. Spörl, M. Huhle, M. Kasper, and T. Seiler, "Increased rigidity of the cornea caused by intrastromal cross-linking," Der Ophthalmologe: Zeitschrift der Deutschen Ophthalmologischen Gesellschaft, vol. 94, no. 12, pp. 902-906, 1997.

[8] G. Wollensak and E. Iomdina, "Long-term biomechanical properties of rabbit cornea after photodynamic collagen crosslinking," Acta Ophthalmologica, vol. 87, no. 1, pp. 48-51, 2009.

[9] S. Kling, L. Remon, A. Pérez-Escudero, J. Merayo-Lloves, and S. Marcos, "Corneal biomechanical changes after collagen crosslinking from porcine eye inflation experiments," Investigative Ophthalmology and Visual Science, vol. 51, no. 8, pp. 3961-3968, 2010.

[10] M. Labetoulle, "An alternative to corneal transplantation in keratoconus treatment?" Journal Français d'Ophtalmologie, vol. 26, no. 10, pp. 1097-1098, 2003.
[11] E. Spoerl, G. Wollensak, and T. Seiler, "Increased resistance of crosslinked cornea against enzymatic digestion," Current Eye Research, vol. 29, no. 1, pp. 35-40, 2004.

[12] P. Vinciguerra, E. Albè, S. Trazza, T. Seiler, and D. Epstein, "Intraoperative and postoperative effects of corneal collagen cross-linking on progressive keratoconus," Archives of Ophthalmology, vol. 127, no. 10, pp. 1258-1265, 2009.

[13] A. Caporossi, C. Mazzotta, S. Baiocchi, and T. Caporossi, "Longterm results of riboflavin ultraviolet a corneal collagen crosslinking for keratoconus in Italy: the Siena eye cross study," American Journal of Ophthalmology, vol. 149, no. 4, pp. 585-593, 2010.

[14] G. D. Kymionis, M. A. Grentzelos, D. A. Liakopoulos et al., "Long-term follow-up of corneal collagen cross-linking for keratoconus-the cretan study," Cornea, vol. 33, no. 10, pp. 10711079, 2014.

[15] A. Theuring, E. Spoerl, L. E. Pillunat, and F. Raiskup, "Corneal collagen cross-linking with riboflavin and ultraviolet-a light in progressive keratoconus," Der Ophthalmologe, vol. 112, no. 2, pp. 140-147, 2015.

[16] A. Gordon-Shaag, M. Millodot, E. Shneor, and Y. Liu, "The genetic and environmental factors for keratoconus," BioMed Research International, vol. 2015, Article ID 795738, 19 pages, 2015.

[17] V. Gonzalez and P. J. McDonnell, "Computer-assisted corneal topography in parents of patients with keratoconus," Archives of Ophthalmology, vol. 110, no. 10, pp. 1412-1414, 1992.

[18] Y. S. Rabinowitz, J. Garbus, and P. J. McDonnell, "Computerassisted corneal topography in family members of patients with keratoconus," Archives of Ophthalmology, vol. 108, no. 3, pp. 365-371, 1990.

[19] A. Saad and D. Gatinel, “Topographic and tomographic properties of forme fruste keratoconus corneas," Investigative Ophthalmology \& Visual Science, vol. 51, no. 11, pp. 5546-5555, 2010.

[20] Y. Wang, Y. S. Rabinowitz, J. I. Rotter, and H. Yang, "Genetic epidemiological study of keratoconus: evidence for major gene determination," American Journal of Medical Genetics, vol. 93, no. 5, pp. 403-409, 2000.

[21] K. Zadnik, J. T. Barr, M. O. Gordon, and T. B. Edrington, "Biomicroscopic signs and disease severity in keratoconus," Cornea, vol. 15, no. 2, pp. 139-146, 1996.

[22] H. Hashemi, A. Beiranvand, M. Khabazkhoob et al., "Prevalence of keratoconus in a population-based study in Shahroud," Cornea, vol. 32, no. 11, pp. 1441-1445, 2013.

[23] A. Ertan and O. Muftuoglu, "Keratoconus clinical findings according to different age and gender groups," Cornea, vol. 27, no. 10, pp. 1109-1113, 2008.

[24] S. Léoni-Mesplié, B. Mortemousque, D. Touboul et al., "Scalability and severity of keratoconus in children," The American Journal of Ophthalmology, vol. 154, no. 1, pp. 56-62.e1, 2012.

[25] T. T. McMahon, T. B. Edrington, L. Szczotka-Flynn et al., "Longitudinal changes in corneal curvature in keratoconus," Cornea, vol. 25, no. 3, pp. 296-305, 2006.

[26] A. H. Al Suhaibani, A. A. Al-Rajhi, S. Al-Motowa, M. D. Wagoner, and A. A. Al-Rajhi, "Inverse relationship between age and severity and sequelae of acute corneal hydrops associated with keratoconus," British Journal of Ophthalmology, vol. 91, no. 7, pp. 984-985, 2007.

[27] J. T. Barr, B. S. Wilson, M. O. Gordon et al., "Estimation of the incidence and factors predictive of corneal scarring in the Collaborative Longitudinal Evaluation of Keratoconus (CLEK) study," Cornea, vol. 25, no. 1, pp. 16-25, 2006. 
[28] S. W. Reeves, S. Stinnett, R. A. Adelman, and N. A. Afshari, "Risk factors for progression to penetrating keratoplasty in patients with keratoconus," American Journal of Ophthalmology, vol. 140, no. 4, pp. 607-611, 2005.

[29] M. O. Gordon, K. Steger-May, L. Szczotka-Flynn et al., "Baseline factors predictive of incident penetrating keratoplasty in keratoconus," American Journal of Ophthalmology, vol. 142, no. 6, pp. 923.e1-930.e1, 2006.

[30] A. Caporossi, C. Mazzotta, S. Baiocchi, T. Caporossi, R. Denaro, and A. Balestrazzi, "Riboflavin-UVA-induced corneal collagen cross-linking in pediatric patients," Cornea, vol. 31, no. 3, pp. 227-231, 2012.

[31] A. Caporossi, C. Mazzotta, A. L. Paradiso, S. Baiocchi, D. Marigliani, and T. Caporossi, "Transepithelial corneal collagen crosslinking for progressive keratoconus: 24-month clinical results," Journal of Cataract and Refractive Surgery, vol. 39, no. 8, pp. 1157-1163, 2013.

[32] P. Vinciguerra, E. Albé, B. E. Frueh, S. Trazza, and D. Epstein, "Two-year corneal cross-linking results in patients younger than 18 years with documented progressive keratoconus," American Journal of Ophthalmology, vol. 154, no. 3, pp. 520-526, 2012.

[33] P. G. Zotta, K. A. Moschou, V. F. Diakonis et al., "Corneal collagen cross-linking for progressive keratoconus in pediatric patients: a feasibility study," Journal of Refractive Surgery, vol. 28, no. 11, pp. 793-796, 2012.

[34] N. Chatzis and F. Hafezi, "Progression of keratoconus and efficacy of corneal collagen cross-linking in children and adolescents," Journal of Refractive Surgery, vol. 28, no. 11, pp. 753758,2012

[35] E. Bakshi, Y. Barkana, Y. Goldich, I. Avni, and D. Zadok, "Corneal cross-linking for progressive keratoconus in children: our experience," International Journal of Keratoconus and Ectatic Corneal Diseases, vol. 1, pp. 53-56, 2012.

[36] A. Magli, R. Forte, A. Tortori, L. Capasso, G. Marsico, and E. Piozzi, "Epithelium-off corneal collagen cross-linking versus transepithelial cross-linking for pediatric keratoconus," Cornea, vol. 32, no. 5, pp. 597-601, 2013.

[37] R. Shetty, H. Nagaraja, C. Jayadev, N. K. Pahuja, M. Kurian Kummelil, and R. M. Nuijts, "Accelerated corneal collagen cross-linking in pediatric patients: two-year follow-up results," BioMed Research International, vol. 2014, Article ID 894095, 5 pages, 2014.

[38] N. Soeters, R. van der Valk, and N. G. Tahzib, "Corneal crosslinking for treatment of progressive keratoconus in various age groups," Journal of Refractive Surgery, vol. 30, no. 7, pp. 454-460, 2014.

[39] E. B. Ozgurhan, N. Kara, K. I. Cankaya, T. Kurt, and A. Demirok, "Accelerated corneal cross-linking in pediatric patients with keratoconus: 24-month outcomes," Journal of Refractive Surgery, vol. 30, no. 12, pp. 843-849, 2014.

[40] R. Arora, D. Gupta, J. L. Goyal, and P. Jain, "Results of corneal collagen cross-linking in pediatric patients," Journal of Refractive Surgery, vol. 28, no. 11, pp. 759-762, 2012.

[41] A. G. Salman, "Transepithelial corneal collagen crosslinking for progressive keratoconus in a pediatric age group," Journal of Cataract \& Refractive Surgery, vol. 39, no. 8, pp. 1164-1170, 2013.

[42] L. Buzzonetti and G. Petrocelli, "Transepithelial corneal crosslinking in pediatric patients: early results," Journal of Refractive Surgery, vol. 28, no. 11, pp. 763-767, 2012.

[43] S. K. Kodavoor, A. Z. Arsiwala, and D. Ramamurthy, "Oneyear clinical study on efficacy of corneal cross-linking in Indian children with progressive keratoconus," Cornea, vol. 33, no. 9, pp. 919-922, 2014.

[44] G. Wollensak, E. Spoerl, and T. Seiler, "Riboflavin/ultraviolet-ainduced collagen crosslinking for the treatment of keratoconus," American Journal of Ophthalmology, vol. 135, no. 5, pp. 620-627, 2003.

[45] D. Viswanathan, N. L. Kumar, and J. J. Males, "Outcome of corneal collagen crosslinking for progressive keratoconus in paediatric patients," BioMed Research International, vol. 2014, Article ID 140461, 5 pages, 2014.

[46] S. Sabti, C. Tappeiner, and B. E. Frueh, "Corneal cross-linking in a 4-year-old child with keratoconus and down syndrome," Cornea, vol. 34, no. 9, pp. 1157-1160, 2015.

[47] F. Raiskup-Wolf, A. Hoyer, E. Spoerl, and L. E. Pillunat, "Collagen crosslinking with riboflavin and ultraviolet-A light in keratoconus: long-term results," Journal of Cataract \& Refractive Surgery, vol. 34, no. 5, pp. 796-801, 2008.

[48] A. Ivarsen and J. Hjortdal, "Collagen cross-linking for advanced progressive keratoconus," Cornea, vol. 32, no. 7, pp. 903-906, 2013.

[49] A. Waszczykowska and P. Jurowski, "Two-year accelerated corneal cross-linking outcome in patients with progressive keratoconus," BioMed Research International, vol. 2015, Article ID 325157, 9 pages, 2015.

[50] R. Shetty, H. Matalia, R. Nuijts et al., "Safety profile of accelerated corneal cross-linking versus conventional cross-linking: a comparative study on ex vivo-cultured limbal epithelial cells," British Journal of Ophthalmology, vol. 99, no. 2, pp. 272-280, 2014.

[51] D. Touboul, N. Efron, D. Smadja, D. Praud, F. Malet, and J. Colin, "Corneal confocal microscopy following conventional, transepithelial, and accelerated corneal collagen cross-linking procedures for keratoconus," Journal of Refractive Surgery, vol. 28, no. 11, pp. 769-775, 2012.

[52] E. B. Ozgurhan, B. I. S. Akcay, Y. Yildirim, G. Karatas, T. Kurt, and A. Demirok, "Evaluation of corneal stromal demarcation line after two different protocols of accelerated corneal collagen cross-linking procedures using anterior segment optical coherence tomography and confocal microscopy," Journal of Ophthalmology, vol. 2014, Article ID 981893, 5 pages, 2014.

[53] A. Leccisotti and T. Islam, "Transepithelial corneal collagen cross-linking in keratoconus," Journal of Refractive Surgery, vol. 26, no. 12, pp. 942-948, 2010.

[54] G. Scarcelli, S. Kling, E. Quijano, R. Pineda, S. Marcos, and S. H. Yun, "Brillouin microscopy of collagen crosslinking: noncontact depth-dependent analysis of corneal elastic modulus," Investigative Ophthalmology and Visual Science, vol. 54, no. 2, pp. 1418-1425, 2013. 


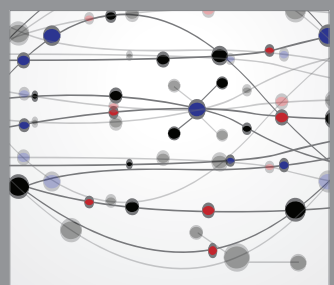

The Scientific World Journal
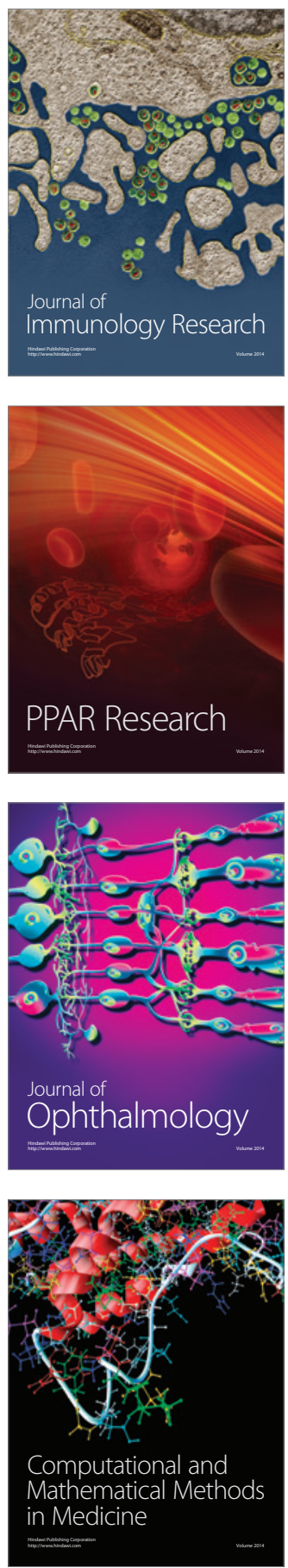

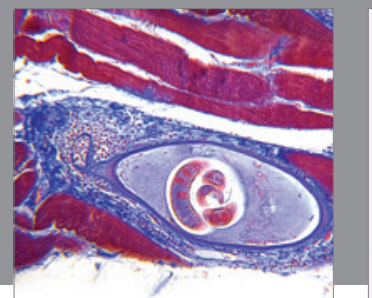

Gastroenterology

Research and Practice
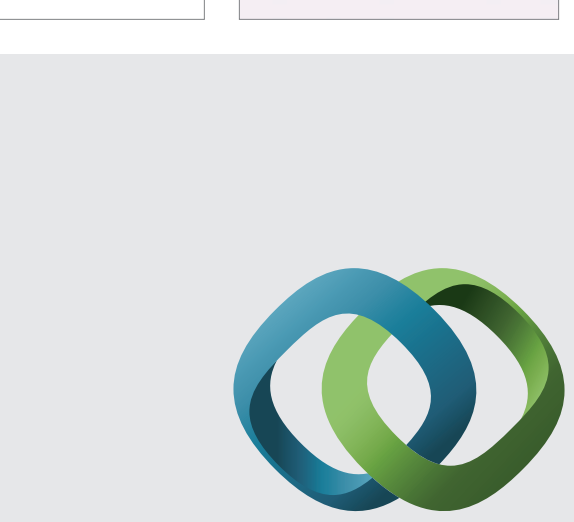

\section{Hindawi}

Submit your manuscripts at

http://www.hindawi.com
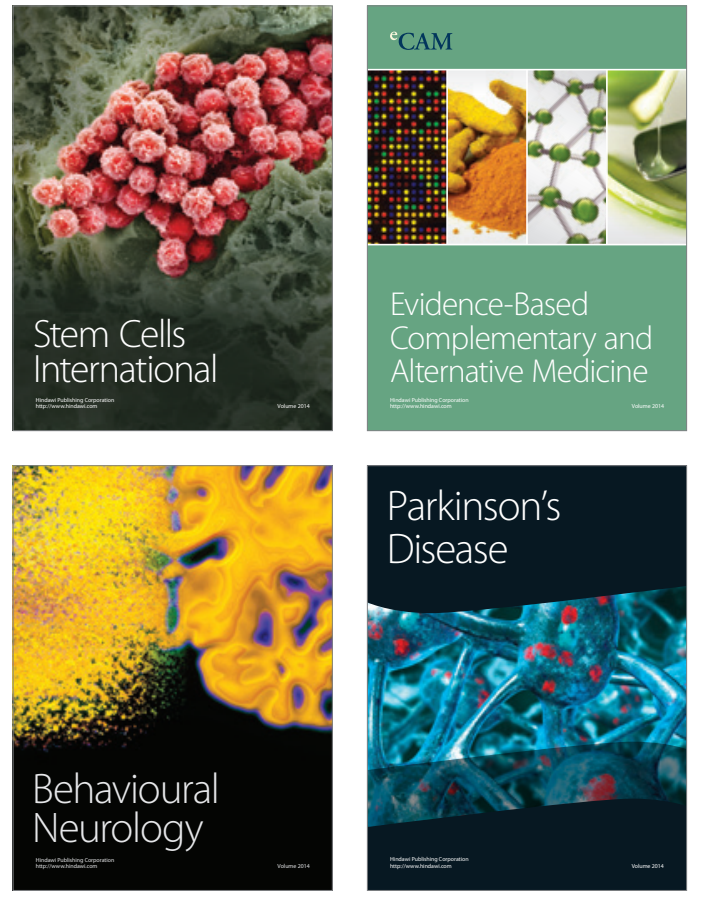
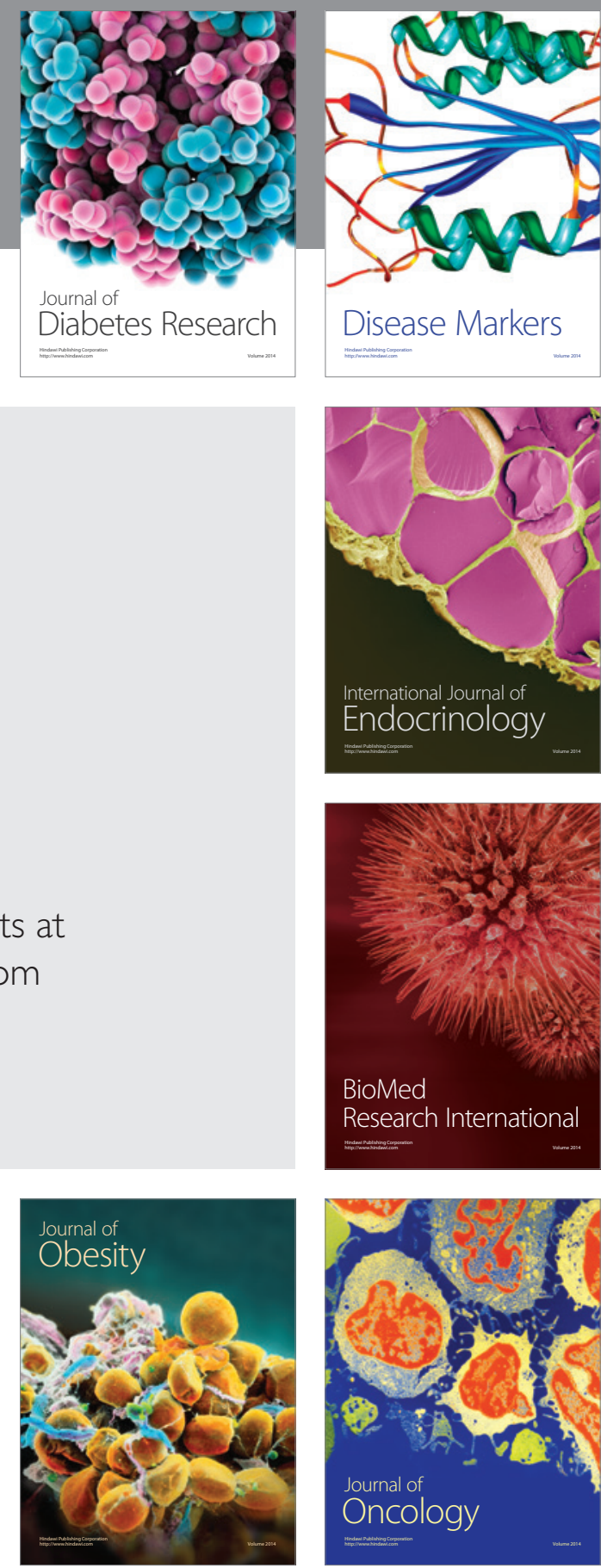

Disease Markers
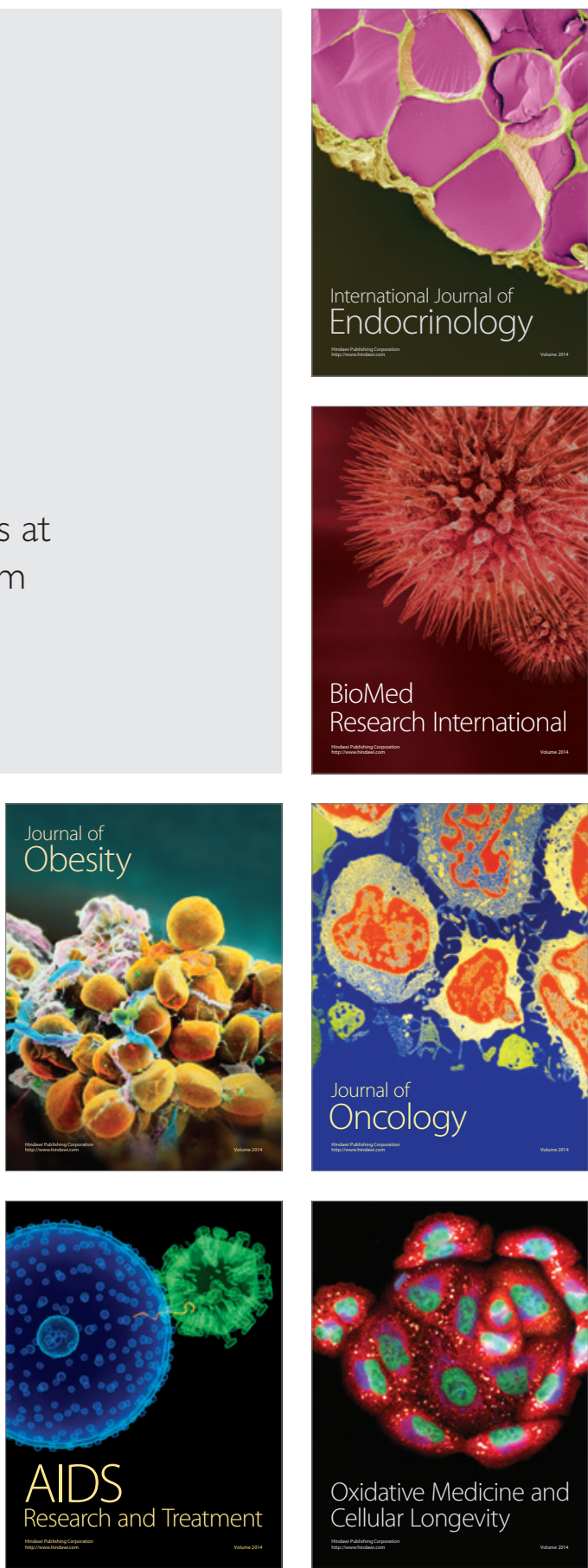